\title{
A complete project environment simulation to improve six sigma training class engagement
}

Chee Kai NGD

Correspondence: bluesea_ck@yahoo.com Medical Devices Company, Singapore, Singapore

\begin{abstract}
Most of the learners view statistical-related training, such as Six Sigma training as a "monotonous" area despite the group discussions, case studies, active summaries, Q\&A sessions, and role-playing being included as part of Six Sigma training today. The learners will be less enthusiastic when similar training manner is repeatedly adopted and becomes predictable. An uninteresting training approach could cause the learners to be disengaged and demotivated to learn and thus cause the training to be ineffective and could potentially hinder the organization strategies. Therefore, to keep the learner more attentive and involved during the Six Sigma training, a fun Six Sigma training approach with a properly designed class game is desirable. The game aims to provide a complete Six Sigma project experience by simulating a real-life competitive atmosphere of commercial industry, which can help the learners to internalize the Six Sigma knowledge and its applications. The Six Sigma game embraces the form of team competition, where it covers two major aspects, namely, (i) Six Sigma expertise on how to formulate a meaningful $y=f(x)$ and (ii) basic element of project management as a coherent approach to Six Sigma training. In this paper, the author adopted the Kirkpatrick learning evaluation model to evaluate how the learners react to the newly implemented Six Sigma game and to gauge how much their know-how improved after the training. The post-training feedback, pre-training, and post-training evaluation suggest that the Six Sigma game can engage and motivate the learners.
\end{abstract}

Keywords: Six sigma competition game, Earning coins, Simulate, Project environment, Classroom engagement, Training effectiveness

\section{Introduction}

Traditional training style such as passive classroom training catering to visual and audio learners could risk being out-of-date and is no longer effective to lead the professional training nowadays. Too much focus on the theory of the Six Sigma or usual training format such as team discussion to build a robust shooting model could result in an uninteresting training. The learners will feel less excited when trainings are conducted in a similar manner again and again and become predictable. How are they going to learn Six Sigma if they feel bored and are less involved in the training?

In addition, the current in-house Six Sigma training may not fully encourage critical thinking skills when the Six Sigma training is designed solely based on a body of

(c) The Author(s). 2017 Open Access This article is distributed under the terms of the Creative Commons Attribution 4.0 International License (http://creativecommons.org/licenses/by/4.0/), which permits unrestricted use, distribution, and reproduction in any medium, provided you give appropriate credit to the original author(s) and the source, provide a link to the Creative Commons license, and indicate if changes were made. 
knowledge of Six Sigma. The single perspective of Six Sigma training limits the learners as they try to extend their Six Sigma learning experiences. The learners may not thoroughly apply the learning through reasoning if the Six Sigma training excludes a simulated real-life competitive project scenario. Specifically, on how to come out with a robust product or optimized process when there are resource, schedule, and scope constraints. The Six Sigma training needs to be relevant to the learners' job environment that motivates the learners to plan and decide according to the available resources and time as well as discuss the use of Six Sigma tools to improve their understanding. However, there have only been a few examples written on how to simulate a real-world Six Sigma project experience using classroom exercises. Therefore, this paper proposes a fun game that includes basic project management knowledge to simulate a real competitive project atmosphere for learners while building their $y=f(x)$ using Six Sigma methodologies as a concurrent approach to Six Sigma training. Furthermore, this paper includes a new game component, i.e., earning coins (resource) to purchase the necessary tools to develop the shooting model, $y=f(x)$ or to construct castles (targets) in the final war (Fig. 1).

The Six Sigma competition game extrinsically and intrinsically motivated the learners who were keen to win or out-strategize the other teams based on what they had learned during the class. The main difference in this Six Sigma competition game in comparison to the catapult competition game suggested by Wezel et al. [1] was that the Six Sigma competition game was divided into two stages. The first phase aimed to earn the coins (resources) by correctly answering the classroom quizzes or sharing opinions with the class. The first phase training process was to engage the learners by creating a cooperative learning within a team. It was an effective approach to improve the team dynamics since the learners came from different departments and levels. It helped to break the ice and got the learners to participate, discuss, plan, work, decide the use of resources, and solve the shooting accuracy and precision issues as a team by applying relevant statistical tools according to Six Sigma methodology. It fostered the application

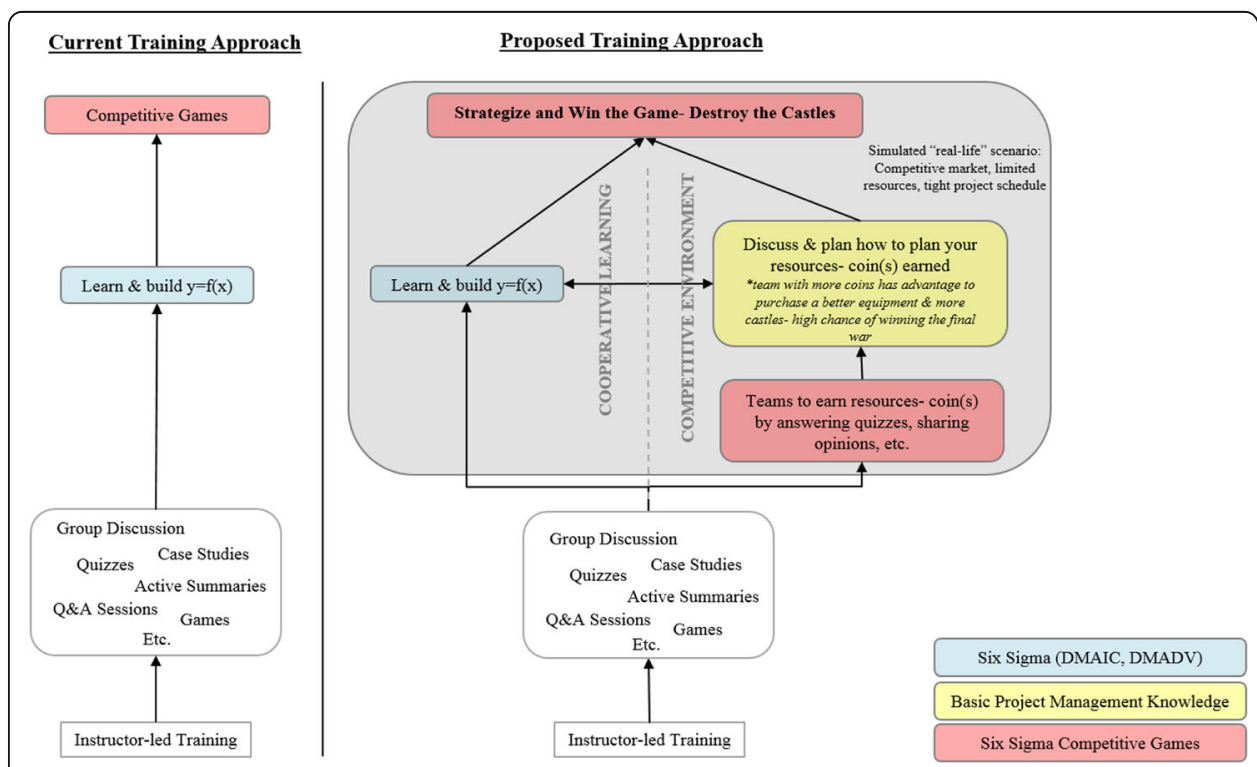

Fig. 1 The comparison between the current and the proposed Six Sigma training approach 
of skills with more confidence and less stress. The second phase centered on a final war (competitive environment) where all the teams needed to prove the robustness of their shooting model, $y=f(x)$ by destroying their opponents' castles (targets). An accurate shot with minimal variation on the castles at varying distances was necessary to triumph in the game. Moreover, the setup cost of the Six Sigma competition game was low compared to the business game described by Hysong et al. [2].

In short, the intent of the game was to help the learners to internalize the Six Sigma learning by applying basic project management skill and making appropriate risk-based decisions, especially when it comes to investing available resources on-hand with the target to win the game. This training approach not only enabled the learners to learn the Six Sigma knowledge, but also encouraged them to think of how to come up with a sound decision after assessing the constraints such as resource, time, and scope. This experience was valuable and motivational because the learners could quickly see and understand the connection between the learning experience and their real-life work.

The Six Sigma training concluded with a measure based on the Kirkpatrick [3] Training effectiveness evaluation model:

Level 1-Reaction to evaluate an immediate learners' satisfaction

Level 2-Learning to find out how much knowledge was acquired

Level 3-Behavior to assess the extent to which knowledge, skills, and attitudes have been transferred from the classroom to the workplace

Level 4-Result to provide the basis for evaluating the benefits of the training to the organization

\section{Review of literature}

Project management is not merely another supplement to an organization's existing Six Sigma method. It is a complementary management methodology that is useful for initiating, planning, executing, monitoring, controlling, and closing the Six Sigma project. The basic project management knowledge, such as defining the scope, organizing people and tasks, and cost/budget can be easily assimilated into the Six Sigma training to portray a real-life project environment with the limited resources available on-hand. Turk [4] explained that project management involves art, science, and luck. Though there are good project management rules to follow, there is also plenty of room for creativity and flexibility based on a common sense approach, where common sense can be applied in understanding the requirements, developing a realistic schedule, and communication to ensure that everyone is aware of what is going on.

According to Armstrong [5], the deficiency model of training happens when learning needs analysis is sometimes assumed to be concerned only with defining the gap between what is going on and what should happen. Learning is much more than only putting things right that have gone wrong. It is more concerned with identifying and satisfying development needs-increasing all-round competence, equipping people to deal with new work demands, multiskilling, and preparing people to take on higher levels of responsibility in the future.

Hysong et al. [2] suggested a business game training approach where a business game is a contrived situation, which embeds players/learners in a simulated business or project environment where they must make management-type decisions such as resource allocation from time to time besides teaching interpersonal skills like 
communication and conflict management. The business games provide excellent opportunities to practise decision-making, problem-solving, and interpersonal interaction skills. However, they deemed that the business games incur a high cost due to a significant amount of work and cost involved in developing the business game. Furthermore, the game is usually limited to a small number of participants, making it difficult for many people to be trained in a short period.

Coronado and Antony [6] described that basic project management skill is one of the key ingredients in the implementation of Six Sigma. Most of the projects fail due to poor management skills or undesired facilitative behaviors. Key elements of project management, time, cost, and quality should be considered to provide the team with the scope, aim, and resources needed to deliver an improvement in the short period and at the lowest cost while meeting requirements.

Mitra [7] argued that many engineering and business students in European universities develop skills in their area of study, but largely without any formal training to help them to integrate the required skills in a holistic problem-solving framework, which requires statistical, management, and technical skills. The future engineers and managers should pick a good blend of statistical, technical, and leadership skills for tackling business problems in organizations.

Pyzdek and Keller [8] suggested that a change agent deficient in soft skills would nearly always be ineffective. Soft skills such as working effectively in small group settings, communicating effectively, negotiation, and conflict resolution mastery are needed as they are applied while honing their technical skills. Therefore, providing a "real world"-based organization-specific challenges is important if the organizations expect the people to internalize how Six Sigma will work in the organization (Pande et al. [9]). The exposure on how to manage or balance the resources (i.e., schedule, scope, cost vs. product performance) and interpersonal skills will give the learner a similar project environment during the Six Sigma classroom training.

Wezel et al. [1] suggested a catapult competition where the learners need to shoot the catapult at random target distances instead of shooting at one fixed target. This approach is suitable to evaluate the robustness of the catapult design, where an accurate shot with the least variation at random target distances is desirable. The trainer can find out how much knowledge was acquired based on the outcome of the shot too.

Burguillo [10] and Cagiltay et al. [11] described that adding the gaming element of competition to a learning environment could achieve a strong motivation and increase learners' learning performance.

Another instructional approach suggested by Attle and Baker [12] is cooperative learning in a competitive environment in the class. It provides opportunities to maximize student learning and professional development, preparing them both to cooperate and compete by structuring learning activities that require them to cooperate in teams that compete against one another.

\section{Design of Six Sigma competition game}

For these reasons, the catapult (Fig. 2) set was suggested as a primary training aid in the Six Sigma training. A catapult offered a tool/process that enhanced the learners' understanding. It supported up to seven factors at two or more levels of experimental 


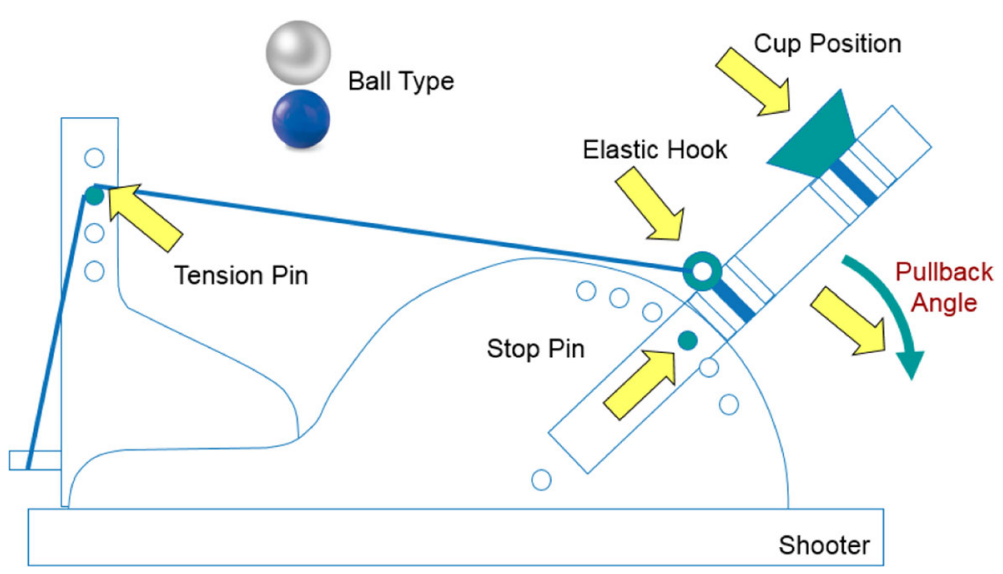

Fig. 2 The catapult apparatus used in the Six Sigma competition game

design as well as both continuous and categorical factors. It provided data for analysis, which could be used for GR\&R, Hypothesis Testing such as $t$ test, one-way ANOVA, regression, DOE, and SPC. A good tie-in between the Six Sigma competition game and the Six Sigma topic was desirable to motivate and ensure engagement during the class. The learners were able to practise the Six Sigma concept and at the same time apply basic project management skills, i.e., how to use the earned coins (resource) to build a robust $y=f(x)$ along the competitive business-like environment learning process.

\section{Team setup}

There is no definitive source to explain an effective class size for Six Sigma training. However, a small class size (10 to 15) was preferable when the goals of training were cognitive and motivational to gain commitment from the learners. To engage different learning styles of the student, the learners were divided into three teams, which consist of cross-functions and mixed level of Six Sigma knowledge. The small group of four to five was desirable to establish participation norms and to create a team climate that encouraged deeper interaction and discussion on establishing $y=f(x)$, especially the introverted learners. The discussion covered the data collection strategy, the decision of what to buy for the catapult tools, the allocation of "right person right job," and data analysis approach. It was observed that a small team was able to draw on the knowledge and skills of all team members rather than creating a situation where the extroverted learners control the learning. A different perspective within the team was desirable in this segment if the team aimed to win the final war at the later stage.

\section{Earn the coins (resources) from quizzes}

Offering the learners the opportunity to earn coins to purchase the catapult and its necessary accessories to build the $y=f(x)$ to win the final war was an excellent source of extrinsic motivational strategy. Therefore, the Six Sigma competition game included a reward (i.e., coins) element in the classroom quizzes as discussed in the earlier section.

There were two forms of quizzes. The first quiz format was to recapitulate the previous day's learning using the "question cards" method. The learners needed to discuss among the team and developed a question list based on what had learned on the previous day before the question given to the opponent team to answer. The 
second one was a Six Sigma pop quiz during the class. The quizzes not only provided immediate feedback to the trainers if any adjustment of the training was needed, but also served as an avenue for the teams to earn their coins (resources) depending on the correctness of the responses. On the other hand, the team would lose its coins for any inappropriate answers. The deduction of coins was not intended as punishment, but it worked as a tool to control the individual learner from simply answering without team discussion. The teams had to accumulate as many coins as possible to better prepare for the final war by purchasing the necessary tools such as catapult, aluminum foil, measuring tapes, different types of ball, rubber band, laser pointer, or clamp to build their shooting model, $y=f(x)$. To make the Six Sigma competition game more enthusing, the team needed to pay a higher price for tools of better quality. For example, 20 coins and 10 coins for a smooth and wrinkled aluminum foil, respectively. This approach helped increase the learners' engagement when the team discussed whether it was worth spending the coins on the specific tools before any decision was made to invest in the tools.

\section{Resource planning}

The primary challenge of the Six Sigma project was to achieve the project's objective within the constraints, i.e., scope, schedule, cost/budget, and quality. The Six Sigma competition game was designed to provide learners a real-world project experience to plan their project based on the available resources on-hand. In this game, the objective and its constraints were as follows:

Objective: To out-strategize their opponents by destroying all the opponents' castles

Requirement: Shooting distance from 1 to $3 \mathrm{~m}$

Scope: Number of factors to study

Schedule: Two hours to build the shooting model, $y=f(x)$

Quality: Desirable accuracy and precision of the shot

Budget: Total coins earned by each team through quizzes

For this reason, the team needed to discuss what to do with their coins. Could they afford to own all the top-quality tools to build the shooting model? If not, what could they do to compromise? In addition, they needed to estimate the number of shots required for the final war as each of the shot costs some coins. Because of this, it was pivotal for the teams to earn as many coins as possible so that they could acquire the top-quality equipment and higher number of shots. Likewise, the teams needed to decide their people resource on the tasks based on individual skill set and interest. The teams required to identify who was the best member to perform tasks as a shooter, assessor, and recorder or to hold and stabilize the catapult. The scope of the shooting process study required prudent planning too. Usually, the expanded scope allowed the team to gain extra information on their shooting process. However, it could also increase the study time and cost due to the higher sample and testing time required.

In essence, the team had to formulate the robust shooting model, $y=f(x)$ in a costefficient and timely manner successfully before they could compete with other teams. It was essential to organize their resources wisely to strike a balance between the scope, schedule of the study, the quality of the shot, and available budget on-hand to win the final war. That is to say, the team needs to obtain the best project outcome using the optimized processes and the right project management methodology. 
Another class activity included as part of the Six Sigma competition game was that a bidding process was used if more than one team intended to purchase the same item. It created excitement in the classroom and thus improved the engagement during the Six Sigma classroom training.

\section{Formulate $y=f(x)$}

The process to obtain an accurate and precise shooting distance model, $Y=f(x)$ centered on Six Sigma methodologies and hands-on activities (kinesthetic learning) throughout the training course. For instance, in the "Define" phase, the team needed to understand the game objective, shooting requirements, and application steps/process flow to identify what were the potential control factors and noises that could affect the accuracy and precision of the shot. The team had to figure out the significant factors by planning their data collection strategy and statistical tools analysis, such as hypothesis testing or regression learned in the "Analyze" phase. The learners were required to observe and conclude if there was any meaningful information from the "Analyze" phase after assessing the measurement error or shooting capability baseline in the "Measure" phase.

During the "Improve"/"Design" phase, DOE or design optimization technique was deployed to establish a meaningful $y=f(x)$. The team had to develop a clear shooting procedure to ensure an accurate hit to the castle (target) with the least variation once the optimized shooting model was verified against the requirements. The appropriate control charts were used to evaluate the stability in the "Control"/"Verify" phase.

To enable Six Sigma knowledge retention, the learners were encouraged to be involved in the team discussion on the following questions. This was to allow the learners to apply the concepts after the presentation of the training material.

- What is the data collection plan before the data collection activities

- What is/are the pattern(s) observed from the raw data

- What is/are the appropriate Six Sigma/statistical tool(s) to analyze the collected data

- How can the team use the analysis outcome to improve the shooting quality using a catapult

- How to document the knowledge (accurate and precise shot) of the catapult shooting process

- Etc.

\section{Final war}

The Six Sigma war game was the final section of the Six Sigma competition game. Before the "war," the teams needed to strategize the number of castles to build and the number of shots required to destroy the opponents' castles (targets) based on their coins (resources) on-hand. Each team had to set up their catapult along the back edge of their region and build their castle(s) within their territory randomly. However, only the rotation of the catapult in the correct direction of the opponent's castle was permissible once the team decided the location of the catapult.

During the war game, the team needed to figure out how to shoot the castle accurately at the specified distance between 1 to $3 \mathrm{~m}$ from the base of the catapult. The team had to measure the distance of the opponent's randomly placed castle and use the 
shooting model, $y=f(x)$, to define the right settings before launching the shot. The last team with an undamaged castle(s) won the war. Prizes could be considered as a token of inspiration for well-formulated shooting model and planning of resources.

\section{Six sigma competition game improves training effectiveness}

The design of the Six Sigma competition game was to motivate the learners to strive for the better to out-strategize the other teams. The extrinsic motivational strategy offered the learners an opportunity to earn coins throughout the training to purchase the catapult and its necessary accessories to build the $y=f(x)$ to win the final war. The game approach developed a fun learning environment that reduced the tense classroom environment, minimized learners' uneasiness, and created a sense of community. It removed the communication barrier within the team and even with the trainer, which was pivotal for classroom engagement. Teamwork brought interest and excitement among the team members to accomplish their goals. For instance, the team had to be more creative, think critically, and constructively challenge assumptions, such as "is it worth to spend this amount of money to buy the equipment?" to come up with a robust shooting model that takes into consideration the constraints in hand to increase the possibilities of winning. Furthermore, they learned communication skills and developed a problem-solving approach that played a great role in their job life.

Through competition, learners not only performed what was required to accomplish the learning objectives but also did the best they can do. The competition was able to turn learners proactive. This learning behavior was clearly observed when the learner volunteered to answer the quizzes during the lesson to gain more coins (resource) to purchase the essential catapult accessories to develop their shooting model. It was an important mechanism for continuous engagement throughout the training process.

\section{Methods}

It is important to determine learners' reactions to the newly designed Six Sigma training approach. Specifically, Six Sigma competition game, which focused comprehensively on (i) basic project management aspect that consists of resource planning based on coins earned from the quizzes, (ii) interpersonal skill during the team discussions, and (iii) building a robust shooting model adopting the Six Sigma methodologies. The Kirkpatrick learning evaluation model was embraced.

For level 1-reaction evaluation, a feedback session to evaluate the six sigma training experience and its war game was performed immediately after the training ended. The feedback session was primed with stimulating questions and open-ended statements that were followed by listening and probing. The feedback was written down and clarified if there was a need to understand the comments in detail. As the raw information from the learners' verbal feedback often appeared in random thoughts, an "Affinity Diagram" approach was adopted. The opinions were categorized by similar content-a step often referred to as "affinity grouping" to derive the feedback information into the summary of the training. Also, the qualitative opinion specific to the newly introduced Six Sigma game was probed to evaluate the training engagement throughout the Six Sigma training process. 
Survey with questions concerning the degree to which they felt the training was effective, the potential for application of the learning to the workplace, and duration of the hands-on and the training was also carried out.

The level 2-learning evaluation used Likert scale survey question with a choice of five pre-coded responses, i.e., 1-no clue, 2-limited knowledge, 3-can use it, 4-comfortable with it, and 5-can teach to allow the learners to gauge themselves how much they improve their know-how according to the specific topics. A pre-training survey and posttraining survey were conducted. Both medians were compared using non-parametric hypothesis testing and graphical analysis to determine if there was sufficient evidence to say that the introducing of Six Sigma competition game helped the training effectiveness using an alpha value of 0.05 .

The Kirkpatrick Evaluation at level 3 was evaluated at the later stage. This allowed time for the learning to be applied and observed if there was any change in job behavior in the workplace. The monthly forum was initiated as one of the ongoing efforts to see if the learners have applied their learning in their project work. Moreover, a Likert scale survey of "Strongly Disagree," "Disagree," "Neutral," "Disagree," and "Strongly Disagree" was designed to get an overall measurement of the sentiment of Six Sigma belief in the organization along with their Six Sigma applications. To do that, a specific question, i.e., "The Six Sigma activities are effective in leading the organization to improve the current product development and process predictability and delivery of outcome" was asked.

\section{Results}

For level 1, the views of the learners were solicited. The questions concerned the degree to which learning experience was valuable, whether they felt the training was effective, and whether they believed they could apply what they learned.

This effectiveness evaluation took place at two different locations, i.e., Singapore and Suzhou, consisting of 37 learners of various functions-R\&D, Quality and Regulatory Affairs, who were involved in new product development and sustaining engineering projects. The qualitative opinions specifically on the newly introduced Six Sigma competition game were consolidated. The learners described the Six Sigma competition game using words such as "engage," "simulate," and "fun".

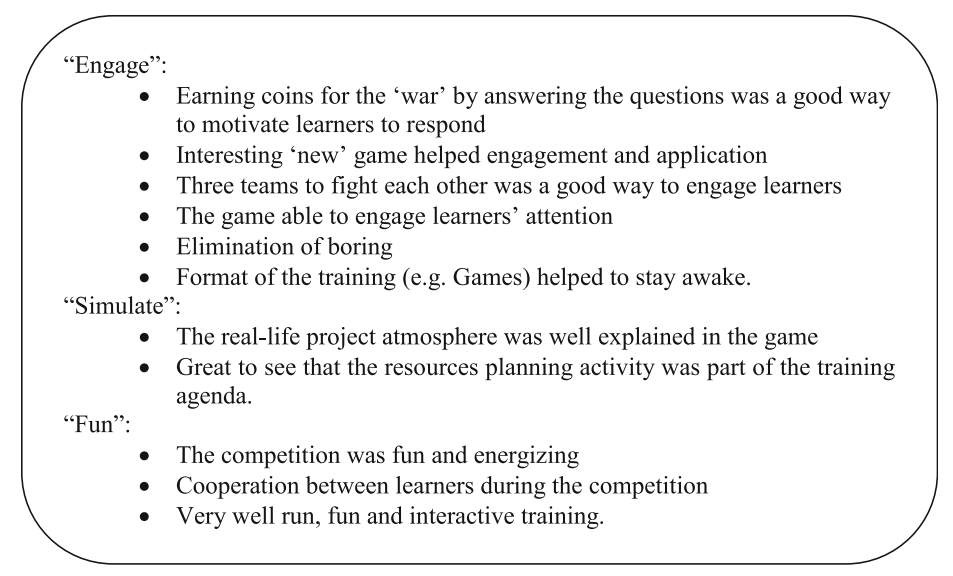

In addition, there was positive feedback on the training environment, where an active involvement of the learners was seen using the Six Sigma competition game. The 
learners learned, discussed, and interacted well with their team member and between the teams under a fun and yet real environment. The learners were freely sharing their catapult work in the class without fear to speak up which enabled the novice learners to learn the Six Sigma tools such as Affinity methods, QFD, Monte-Carlo simulation, Minitab software and understand when and where to apply the tools during the product development process. Likewise, the more experienced learners felt that they gained a more in-depth understanding of Six Sigma tools from the class discussion besides reinforced certain statistical tools applications such as Hypothesis Testing and DOE through the classroom workshops.

From the post-training survey evaluation (Fig. 3), approximately two-thirds of the learners felt that the Six Sigma training and its simulated project environment game were either very or extremely effective and $92 \%$ of the learners deemed that the handson using Six Sigma competition game addressed the learners' needs well. The survey result was in line with the feedback session after the training. Moreover, more than $95 \%$ of the learners said that they are likely to utilize the learning soon.

For Kirkpatrick Level 2, a Likert-based survey (Fig. 4) was carried out to measure how well the learners acquired the knowledge from this training. The study suggested that the Six Sigma training, and its competition game were able to engage the learner during the training and improved their understanding of each of the Six Sigma topics judging from the average level of "Limited Knowledge" to "Can Use It".

For Kirkpatrick Level 3, a sample of 26 respondents consisting of R\&D function and Quality function from new product development and sustaining engineering projects were collected at a later stage to understand the overall sentiment of Six Sigma methodology (Fig. 5). The result showed that most of the learners believe that Six Sigma can improve the performance process, which is vital in cultivating Six Sigma culture in the organization.

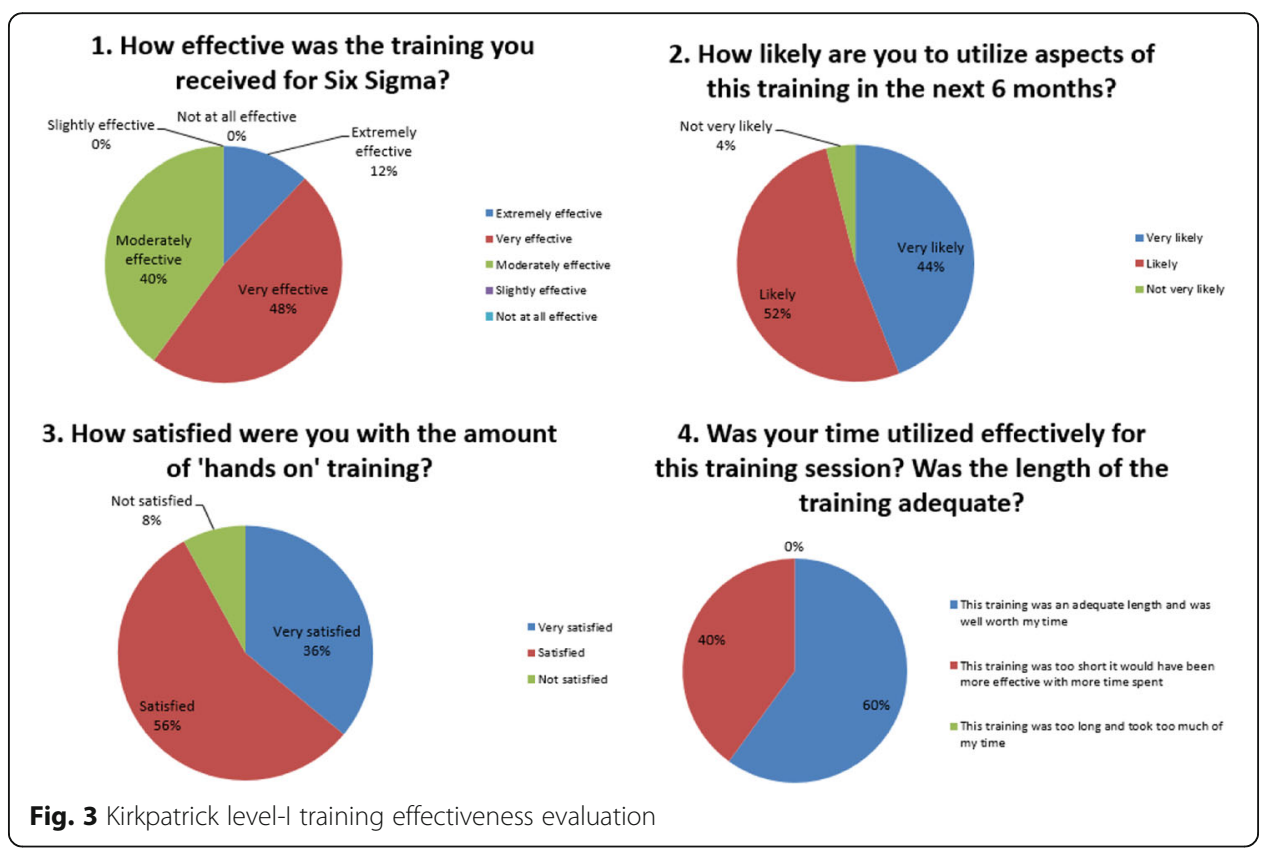




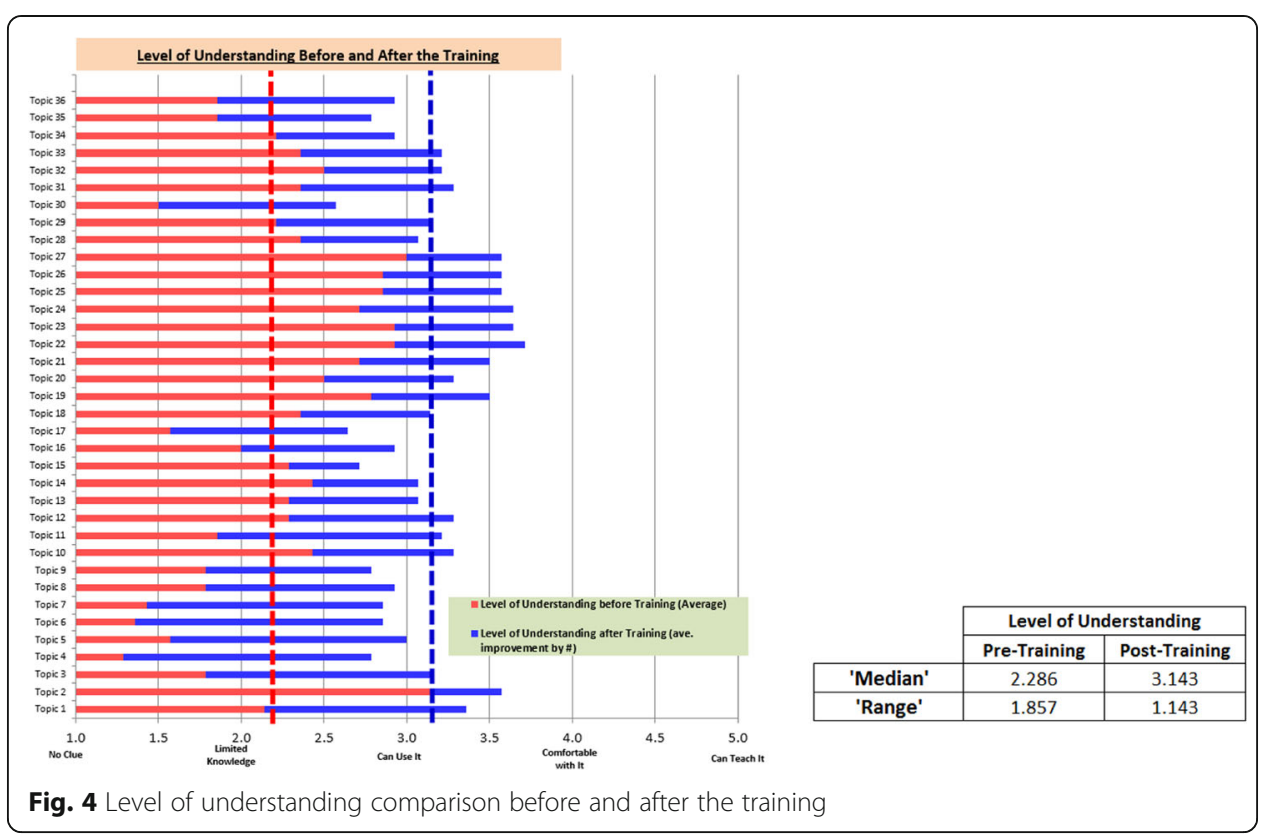

\section{Discussion}

For Kirkpatrick level 1 effectiveness assessment, the learners felt that the training was effective and they are likely to utilize the Six Sigma tools shortly. The qualitative opinions from the learners suggested that the Six Sigma competition game was a strong motivation tool besides being an excellent class activity to engage the learners during the Six Sigma training. It was observed that the learners were actively involved and contributed to the team discussion. The Six Sigma competition game using a catapult was fun and interactive. It provided learners a platform to manage the issues faced in a controlled and yet real project experience, especially in this time of turmoil and a tight

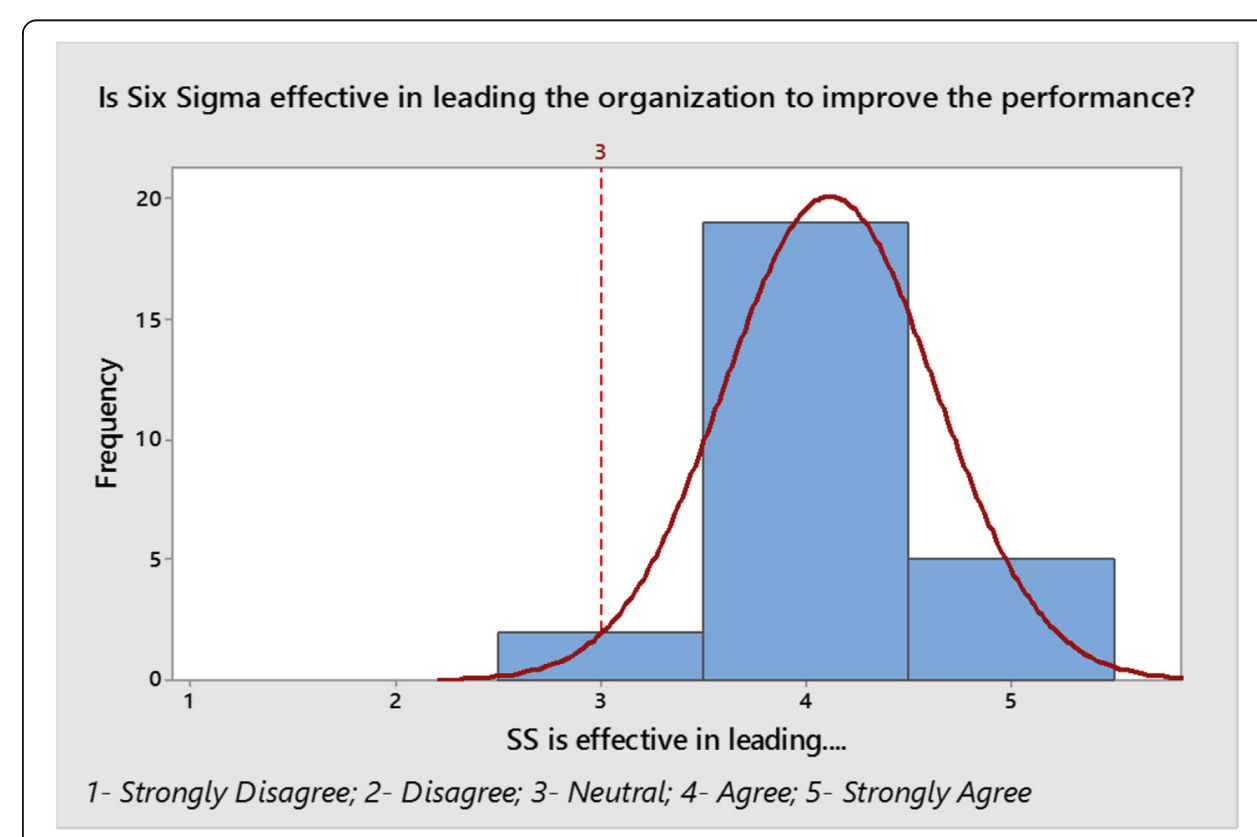

Fig. 5 The measure of overall sentiment of Six Sigma belief 
budget. The team needed to think how to be efficient with earning coins, using the right resources for the task, and having a robust shooting model, $y=f(x)$ to compete with other teams.

As the ordinal data was collected in the pre-training and post-training survey with the same learners present in both surveys for each of the topics, a signed-rank test (instead of Wilcoxon signed-rank test) was applied (due to asymmetrically shaped distribution of difference, Fig. 6) to evaluate if there was sufficient evidence to show that the learners learned from the training. In addition, a histogram was plotted to discover the difference in the understanding before and after the training (Fig. 7). As the $p$ value is less than 0.05 (Fig. 8), it can be concluded that the learners demonstrated statistically significant improvement in the level of understanding from "Limited Knowledge" (median of 2.29) to "Can Use It" (median of 3.14). The behavior of "I can use it" suggested the learners' confidence in using the knowledge on the job. In other words, the Six Sigma training adopting a simulated project environment (Six Sigma competition game) enabled better training engagement, and it successfully improved the learners' competency by approximately $37 \%$. Moreover, the training helped to promote similar language, as seen by a narrower variation among the learners with a "range" from 1.86 to 1.14 .

It is believed that learner achievement may increase while the "engagement gap" closes. In other words, the Six Sigma competition game provided a right training engagement environment for learning (Kirkpatrick level 1) which enabled the learners to internalize the learning, increase the learners' attention, and motivate them to practise higher level critical thinking skills (Kirkpatrick level 2). The knowledge gained from the training laid the foundation for the transfer of the learning to the workplace (Kirkpatrick level 3) and subsequently could enable the desired changes in organizational performance (Kirkpatrick level 4).

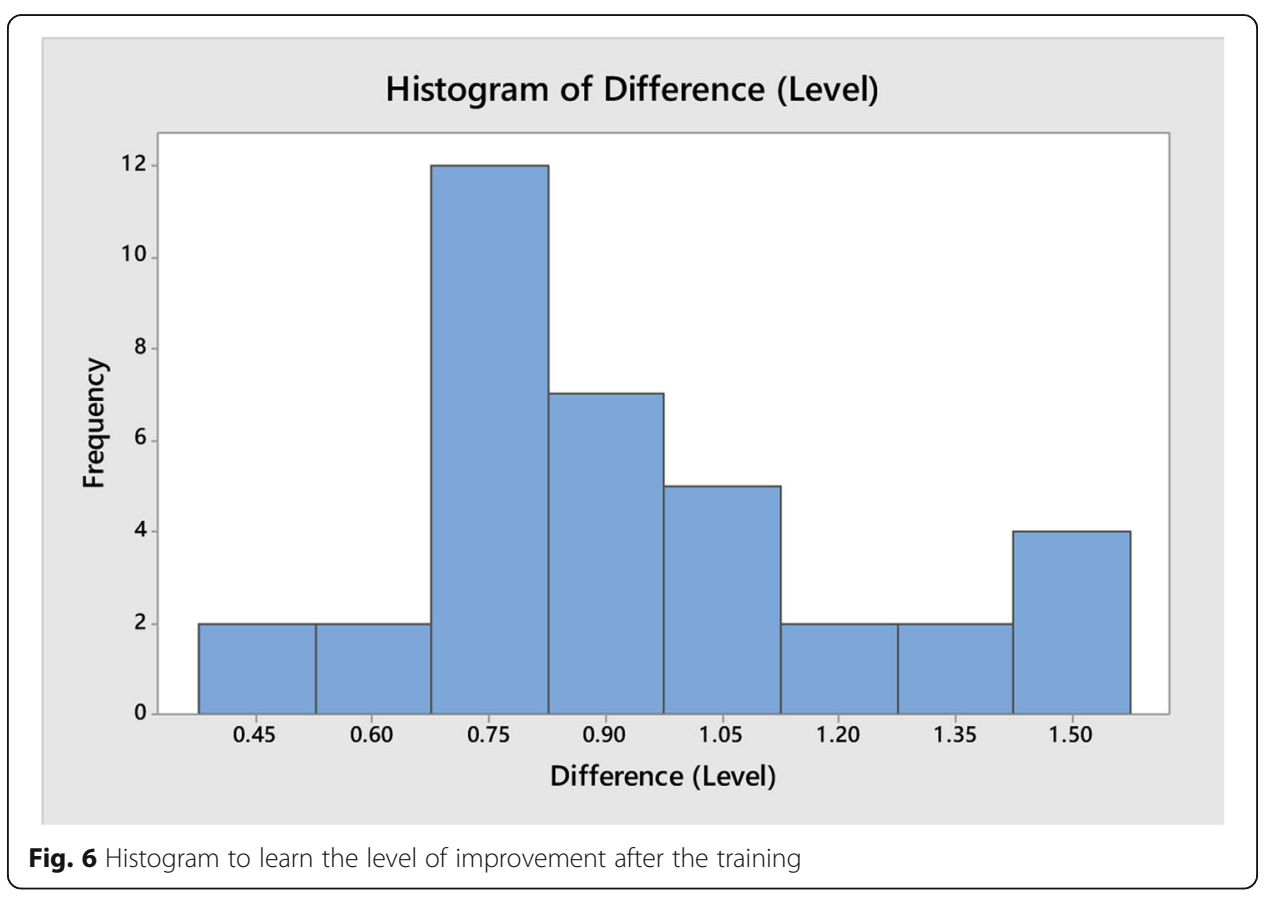




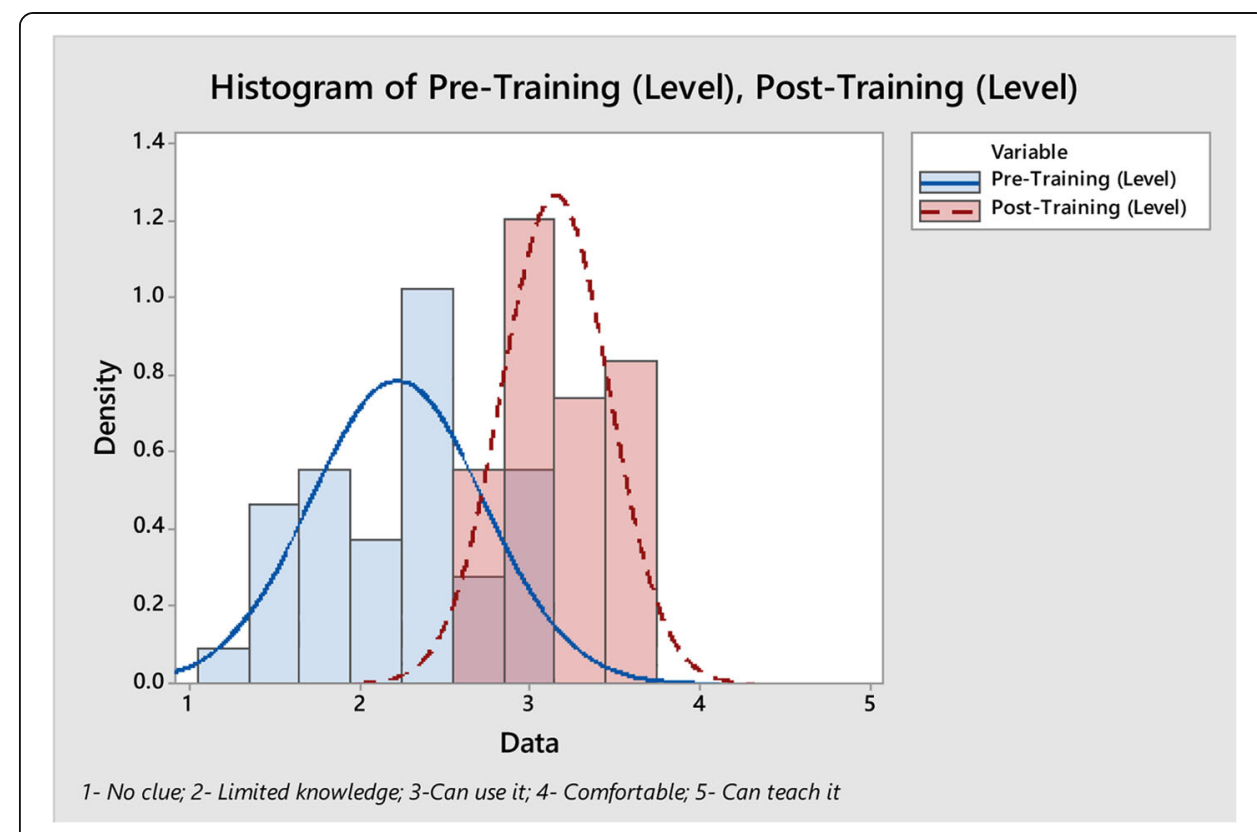

Fig. 7 Histogram to discover the difference in understanding before and after the training

However, for Kirkpatrick levels 3 and 4 evaluation to be more relevant, more time is needed to monitor the change in behavior. For instance, any noticeable change in the activity and performance of the learners after the training, how changes in learners' job performance are affecting business performance or financial benefits. Despite the increased level of evaluation difficulty when elevating to another higher level of the Kirkpatrick model, the assessment methodology was discussed with management on how the success will be measured. Early successes such as cycle time improvement, products meeting customer requirements and manufacturing scrap improvement were observed.

\section{Practical implications}

The newly designed Six Sigma competition game created a fun and improved engagement. However, it could lead to side effects such as increasing fear of failure, creating winners/ losers, cheating/breaking the spirit of the game, and creating an emotional atmosphere in the class or division between learners in the class if managed inappropriately.

Another point to note is that one trainer to 10 to 15 learners is probably a good ratio for passive learning. However, a single trainer for the similar class size might not be feasible for active learning which includes many hands-on exercises in the entire Six

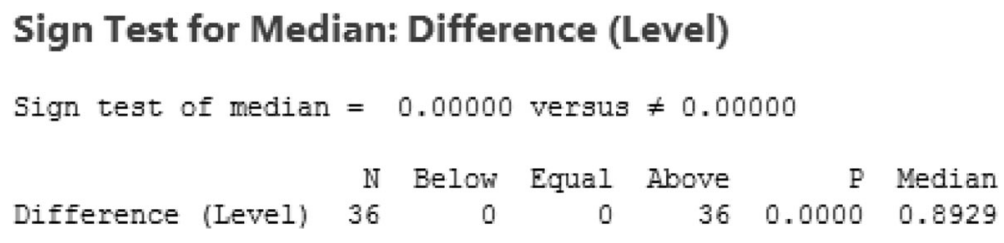

Fig. 8 Median of understanding comparison before and after the training 
Sigma training process. The pace of the training or workshops could be too fast for some learners and cause $8 \%$ of the learners to be dissatisfied with the "hands-on" exercises (Fig. 3). For this reason, co-trainer(s) is/are suggested for the upcoming training. Nevertheless, there is no definitive source to define the right class size for Six Sigma training as the class size usually depends on the intent of the training, training duration, and the level of mastery in the topics.

The difficulty of evaluation at the higher level of Kirkpatrick model is another potential challenge in the organization as there are many factors could contribute to the results other than the training. Because of the complexity of taking into account the factors, there is always a discussion on how to correlate the Six Sigma training to the company top-line and bottom line accurately.

\section{Conclusion}

The lack of engagement and motivation in classroom-based training is one of the primary Six Sigma training issues being faced in most of the organizations nowadays. The narrow focus of the current Six Sigma training only gives a partial picture of Six Sigma project experience without considering the project management aspects such as the planning of resources. To address this concern, this paper offers a broader and more fun training approach, i.e., an extrinsically and intrinsically motivating Six Sigma competition game where it provides a complete real-life project experience. Learners need to discuss, plan, and decide on how to make use of their earned resources- "coins" to develop their shooting model- " $y=f(x)$ " by applying what they learned in Six Sigma training course if they are keen to triumph in the game. The cooperative learning within the team and competition-based learning increase the level of intensity and excitement in the Six Sigma training and thus enables an improved engagement that leads to a more effective understanding and retention of knowledge. Conversely, it can affect the learning environment in the class if managed unwisely. After all, one size does not fit all. Training design needs to be relevant to the organization and functions' needs and delivered when they require it and in a format that the organization finds feasible.

Abbreviations

ANOVA: Analysis of variance; DOE: Design of experiments; GR\&R: Gauge repeatability and reproducibility; QFD: Quality function deployment; R\&D: Research and development; SPC: Statistical process control

Acknowledgements

The author would like to express his appreciation to Prof. Uk Jung for recommending this paper for publication. The author would also like to extend his thanks to Prof. Wan Shin and Prof. Sang M. Lee for the constructive comments that greatly improved this article. Finally, the author wishes to thank Rajesh Gur and Matthew Woo for their support in this paper.

Funding

No funding was used for this research.

Author's information

The author is a Staff Quality Engineer at Medical Devices Company in Singapore. He is also a Six Sigma trainer in the company. He obtained his Master of Science in Industrial \& Systems Engineering from the National University of Singapore. He is a Senior Member of American Society for Quality (ASQ), Certified Master Black Belt, Certified Manager of Quality / Organizational Excellence, and Certified Reliability Engineer with the ASQ and is also a Certified Quality Engineer with Singapore Quality Institute (SQI). His interest is mainly in Six Sigma change management and its application. 


\section{Publisher's Note}

Springer Nature remains neutral with regard to jurisdictional claims in published maps and institutional affiliations.

Received: 19 January 2017 Accepted: 21 September 2017

Published online: 06 October 2017

\section{References}

1. Wout van Wezel, Elliot Bendoly, Daniel G. Bachrach (2015) The Handbook of Behavioral Operations Management-social and psychological dynamics in production and service settings. Oxford University Press

2. Sylvia J. Hysong, Laura Galarza, Albert W. Holland (2007) A review of training methods and instructional techniques. NASA

3. Kirkpatrick DL (1994) Evaluating training programs: the four levels. Berret-Koehler, San Francisco

4. Turk W (2008) Common sense project management. ASQ Quality Press, Milwaukee, Wisconsin

5. Armstrong M (2006) A Handbook of Human Resource Management Practice. Kogan Page, London and Philadelphia

6. Coronado RB, Antony J (2002) Critical success factors for the successful implementation of six sigma projects in organisations. TQM Mag 14(Iss 2):92-99

7. Mitra A (2004) Six sigma education: a critical role for academia. TQM Mag 16(Iss 4):293-302

8. Thomas Pyzdek, Paul Keller (2014) The Six Sigma Handbook: a complete guide for green belts, black belts, and managers at all levels. McGraw-Hill

9. Peter S. Pande, Robert P. Neuman, Roland R. Cavanagh (2000) The Six Sigma way. McGraw-Hill

10. Burguillo JC (2010) Using game theory and competition-based learning to stimulate student motivation and performance. Comput Educ. doi:10.1016/j.compedu.2010.02.018

11. Cagiltay NE, Ozcelik E, Ozcelik NS (2015) The effect of competition on learning in games. Comput Educ 87:35-41

12. Attle S, Baker B (2007) Cooperative learning in a competitive environment: classroom applications. Int J Teach Learn High Educ 2007 19(Number 1):77-83

Submit your manuscript to a SpringerOpen ${ }^{\circ}$ journal and benefit from:

- Convenient online submission

- Rigorous peer review

Open access: articles freely available online

High visibility within the field

Retaining the copyright to your article 